\title{
Haemolytic uraemic syndrome - a rare case report of bloody diarrhoea in adults
}

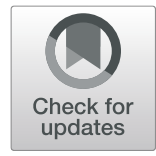

\author{
Shiva Thambiah Radhakrishnan ${ }^{1 *} \mathbb{D}$, Aruchuna Ruban ${ }^{2}$, Aarthy Kanmany Uthayakumar ${ }^{3}$, Patrizia Cohen $^{4}$, \\ Jeremy Levy ${ }^{5}$ and Julian Teare
}

\begin{abstract}
Background: Haemolytic uraemic syndrome is a rarely seen in adults often leading to critical illness. This case highlights how difficult it can be to establish a diagnosis and treat when a patient presents with bloody diarrhoea.

Case presentation: A 17-year-old Iraqi man presented to the emergency department with abdominal pain and bloody diarrhoea. He was initially treated as acute appendicitis, undergoing an appendectomy but following a recurrence in his symptoms a colonoscopy was performed. A diagnosis of shiga toxin-producing Escherichia coli leading to HUS was suspected following histology obtained at colonoscopy and this was confirmed on antibody testing. Despite intravenous fluids and supportive therapy the patient's symptoms and condition deteriorated. He developed seizures and acute renal failure requiring intubation and plasma exchange in the intensive care setting. He eventually required treatment with ecluzimab therapy; a monoclonal antibody and subsequently made a full recovery.

Conclusions: Haemolytic uraemic syndrome is a triad of progressive renal failure, thrombocytopenia and haemolytic anaemia which is a condition rarely seen in adults. It is usually associated with an E. coli infection and supportive therapy remains the mainstay of treatment.
\end{abstract}

Keywords: Bloody diarrhoea, Haemolytic uraemic syndrome, E.coli 0157, Plasma exchange, Shiga-toxin

\section{Background}

Infection with E.coli 0157 can present with a variety of symptoms including bloody diarrhoea and abdominal cramps. The bacterium is commonly transferred by a feco-oral route and undercooked meat is a known culprit [1]. This infection is linked to Haemolytic uraemic syndrome (HUS) which presents with the triad of progressive renal failure, thrombocytopenia and haemolytic anaemia. HUS can be classified as either typical (diarrhoea associated) or atypical (non-diarrhoea associated such as following a urinary tract infection), [2]. We present a case of a 17-year-old male with bloody diarrhoea who proceeded to be affected by severe HUS including neurological sequalae. Our case highlights the difficulties in establishing a diagnosis and treatment when a patient presents with bloody diarrhoea.

\footnotetext{
* Correspondence: shiva.radhakrishnan@nhs.net

${ }^{1}$ Department of Gastroenterology, Imperial College Healthcare NHS trust, St Marys Hospital, London W2 1NY, England

Full list of author information is available at the end of the article
}

\section{Case presentation}

A 17-year-old Iraqi male presented to the emergency department with a 2 day history of right iliac fossa pain, vomiting and a few episodes of diarrhoea. A clinical diagnosis of appendicitis was made and he was treated with intravenous antibiotics and underwent an appendicectomy, the histology of which was normal. At the time of the operation, the surgeon noted the right colon appeared to be inflamed. The patient had no prior medical history and his family history was nil of note.

A computed tomography (CT) scan was performed postoperatively which showed thickening of the ascending colon with some submucosal oedema in the caecum with associated local regional lymph nodes. However the patient's condition improved enough to be sent home the day after his operation.

Two days later he returned to hospital with bloody diarrhoea up to ten times a day, with associated fever and a tender abdomen. Baseline admission investigations are shown in Table 1. Initial stool cultures were negative including for Escherichia coli 0157 (E. coli), and the patient was started on intravenous cefuroxime and 
Table 1 Baseline admission investigations

\begin{tabular}{lll}
\hline & Measurement & Normal Range \\
\hline Haemoglobin & $182 \mathrm{~g} / \mathrm{L}$ & $130-168 \mathrm{~g} / \mathrm{L}$ \\
Mean cell volume & $88.2 \mathrm{fL}$ & $83.5-99.5 \mathrm{fL}$ \\
Platelets & $332 \times 10^{9} / \mathrm{L}$ & $130-370 \times 10^{9} / \mathrm{L}$ \\
White cell count & $12.4 \times 10^{9} / \mathrm{L}$ & $4.2-10.6 \times 10^{9} / \mathrm{L}$ \\
Neutrophils & $7.7 \times 10^{9} / \mathrm{L}$ & $2.0-7.1 \times 10^{9} / \mathrm{L}$ \\
Lymphocytes & $3.4 \times 10^{9} / \mathrm{L}$ & $1.1-3.6 \times 10^{9} / \mathrm{L}$ \\
Sodium & $141 \mathrm{mmol} / \mathrm{L}$ & $133-146 \mathrm{mmol} / \mathrm{L}$ \\
Potassium & $4.1 \mathrm{mmol} / \mathrm{L}$ & $3.5-5.3 \mathrm{mmol} / \mathrm{L}$ \\
Urea & $3.6 \mathrm{mmol} / \mathrm{L}$ & $2.5-7.8 \mathrm{mmol} / \mathrm{L}$ \\
Creatinine & $68 \mu \mathrm{mol} / \mathrm{L}$ & $60-125 \mu \mathrm{mol} / \mathrm{L}$ \\
Bilirubin & $9 \mu \mathrm{mol} / \mathrm{L}$ & $0-21 \mu \mathrm{mol} / \mathrm{L}$ \\
Alkaline phosphatase & $106 \mathrm{IU} / \mathrm{L}$ & $60-370 \mathrm{IU} / \mathrm{L}$ \\
Alanine aminotransferase & $15 \mathrm{IU} / \mathrm{L}$ & $0-40 \mathrm{IU} / \mathrm{L}$ \\
Abdominal radiograph & No toxic megacolon & \\
\hline
\end{tabular}

metronidazole. An abdominal radiograph did not reveal colonic dilatation. A colonoscopy was performed which showed patchy pan-colitis, maximal in the ascending and descending colon.

Given the age of the patient and location of his symptoms, plus the initial findings on the CT scan, a diagnosis of inflammatory bowel disease was considered. The other main differential was an infective colitis caused by Campylobacter, Shigella, E. coli or Clostridium difficile. Tuberculosis (TB) was another possibility and although the patient was originally from Iraq there was no recent history of foreign travel or relevant contact history of TB exposure. The appearances at colonoscopy were most suggestive of Crohn's disease so the patient was commenced on intravenous hydrocortisone. Colonic biopsies were taken with the histology results shown in Fig. 1.

Despite $24 \mathrm{~h}$ of steroid therapy, the patient still had on-going bloody diarrhoea although his pain had now settled. His renal function had declined from a normal baseline to a serum urea of $11.3 \mathrm{mmol} / \mathrm{L}$ and a serum creatinine of $170 \mu \mathrm{mol} / \mathrm{L}$, and despite being adequately hydrated with intravenous fluids he became anuric. $\mathrm{He}$ was also noted to be thrombocytopenic with a platelet count of 81 . Additionally, the patient became anaemic and his blood film showed Red cell fragments: 10 fragments per $\times 40$ objective field, indicating haemolysis. Clinically the patient became disorientated and agitated and he rapidly deteriorated developing partial-complex seizures. This rapid deterioration required intubation and he was promptly admitted to the intensive care unit (ITU). A diagnosis of typical Haemolytic Uraemic Syndrome (HUS) was made following the history of gastrointestinal illness coupled with an acute kidney injury and thrombocytopenia. His levels of ADAMTS13 were

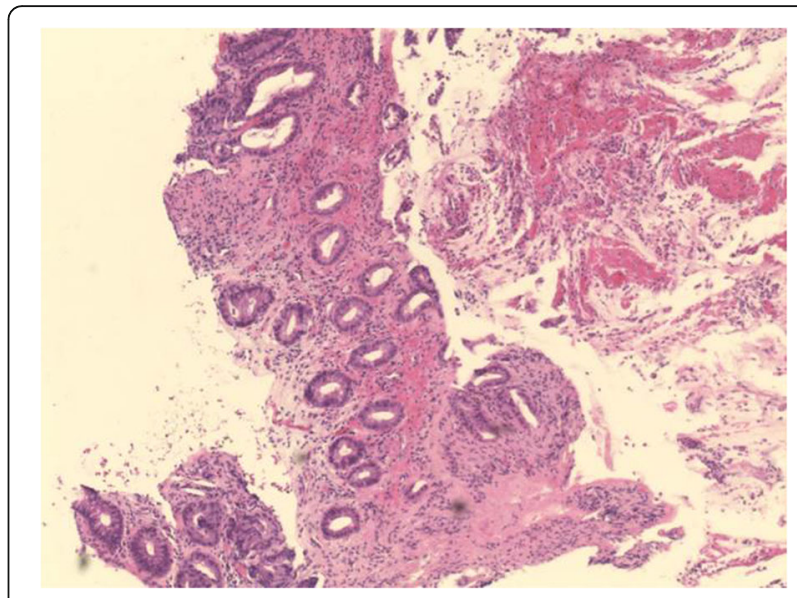

Fig. 1 "Large bowel mucosa showing withered atrophic crypts near the surface and lamina propria hyalinisation along with haemorrhage. Free lying pseudomembranous exudate composed of mucus, inflammatory exudate and blood is noted near the luminal surface. These findings are highly suggestive of enterohaemorrhagic E.coli"

normal, making a diagnosis of Thrombotic Thrombocytopenic Purpura (TTP) less likely. The patient received haemofiltration and plasma exchange with fresh frozen plasma but showed little signs of improvement so after 10 days he was commenced on Eculizumab a monoclonal antibody. He remained on the ITU for a further 35 days and spent a further 28 days on renal high-dependency unit during which time he gradually improved. $\mathrm{He}$ remained seizure free with normalisation of his platelets and biochemical profile and was discharged well from hospital.

\section{Discussion and conclusions}

HUS is a rare condition characterized by progressive renal failure, thrombocytopenia and haemolytic anaemia. It can be classified as either typical (diarrhoea associated) or atypical (non-diarrhoea associated such as following a urinary tract infection), [2]. A well-recognised cause of HUS is due to infection with shiga toxin-producing bacteria, the most common of which is E.coli O157: H7, [3]. This mainly occurs in childhood, and is characterised by a prodromal acute gastroenteritis followed by haemolytic anaemia, thrombocytopenia and acute kidney injury.

Shiga toxin releasing E.coli (STEC) gastroenteritis can be difficult to diagnose as patients may not present with all the hallmark features. Bloody diarrhoea can occur a median of 3 days after ingestion of contaminated food and some patients may also report to suffer from severe abdominal pain and painful defecation, [4]. The latter may help to distinguish STEC from other causes of bacterial gastroenteritis where these symptoms would be unusual, [5]. 
The primary pathophysiological mechanism in typical HUS is vascular endothelial cell injury by both inflammatory and non-inflammatory mechanisms, such as cytokine release, [2]. Renal dysfunction in HUS is thought to be caused by microthrombi of platelets and fibrin in arterioles and capillaries, [6]. Approximately $40 \%$ of patients with STEC require renal replacement therapy, and of these, $20 \%$ will have permanent renal dysfunction, [7]. Coagulopathy and thrombocytopenia occur due to increased platelet consumption. Fragmented red cells, a key feature of HUS, is due to mechanical damage from shear stress in fibrin lined vessels as well as peroxidative damage.

Our patient did have microangiopathic haemolysis, acute renal failure, thrombocytopenia and was eventually found to be STEC antibody positive, which confirmed a diagnosis of typical HUS, [8]. The cause of his seizures was unclear but neurological involvement in HUS is a recognized complication and is the most frequent cause for fatalities, [7]. The pathophysiology is thought to be multifactorial and still poorly understood but may be due to a combination of microinfarctions in key anatomical regions such as the brainstem or the effect of increased inflammatory cytokines seen to be present in higher concentrations in patients with neurological complications such as seizures and encephalopathy, [9].

Neurological complications are also a clinical feature of thrombotic TTP and both TTP and HUS are considered to be on a spectrum of thrombotic microangiopathies, [10]. Though TTP shares a similar clinical picture, in this syndrome there is a deficiency or formation of antibodies to ADAMTS13, a von Willebrand cleaving protease which helps to differentiate the two conditions, [11].

Supportive therapy remains the mainstay of treatment in HUS with adequate fluid rehydration where required, [12]. The role of antibiotics is controversial in STEC gastroenteritis with some evidence that antibiotic therapy may be detrimental triggering further release of shiga toxin by bacterial lysis [13-15], which may explain the delayed deterioration in our patient.

A likely contribution to the pathogenesis of STECHUS is activation of the alternative complement pathway and so patients with life threatening complications may receive benefit with short term therapy with ecluzimab, a monoclonal antibody against $\mathrm{C}$, which inhibits terminal complement complex formation. This has already been reported as an effective treatment in atypical HUS where the role of the complement pathway is well established, $[5,15,16]$. In a case series following an outbreak of STEC (E.coli O104:H4) in Germany, rapid clinical improvement following eculizumab was reported, $[17,18]$. All patients had renal failure and neurological involvement which had not responded to plasma exchange. Due to the cost of the drug, its use is limited to only the most severe cases and therefore treatment is often delayed, [19]. Within a paediatric population, early treatment of HUS with eculizimab in patients with neurological complications led to better outcomes, compared to delayed therapy initiation in patients with rapidly progressive HUS, [20].

Plasma exchange therapy in typical HUS is controversial in adults as there is a lack of evidence for its efficacy but it is used in some cases where severe neurological abnormalities exist, [21, 22]. In addition, immunoadsorption with intravenous immunoglobulins (IVIG) can also be used in this setting and has been shown to lead to improvement [23]. The rationale is based on a suspected immune-mediated mechanism to neurological sequelae, which explains the delayed onset of these symptoms in disease course.

\section{Learning points}

- HUS secondary to STEC is well described condition in the paediatric population but its incidence and epidemiology in adults is relatively unknown.

- The classic triad in HUS is haemolytic anaemia, acute renal failure and thrombocytopenia. Early checking of ADAMTS13 and for STEC is advised if indicated.

- Antibiotics are relatively contraindicated in E.coli associated HUS.

- The role of the histopathologist is crucial in the recognition of E.Coli as this can speed up diagnosis and onward management decisions.

- Treatment is largely supportive with fluid resuscitation and dialysis if required, although more recently ecluzimab and immunoadsorption provide additional treatment options for patients who are not clinically improving.

\section{Abbreviations}

CT: Computed tomography; E.coli: Escherichia coli; HUS: Haemolytic uraemic syndrome; ITU: intensive care unit; IVIG: intravenous immunoglobulins; STEC: Shiga toxin releasing E.coli; TB: Tuberculosis; TTP: Thrombotic

Thrombocytopenic Purpura

\section{Authors' contributions}

STR admitted and reviewed the patient when they were first admitted, was also responsible for the initial case report write up. AR edited and reviewed the manuscript. AKU reviewed and edited the manuscript and helped with the literature review. PC performed histological analysis of the patient's colonic biopsies. JL reviewed the patient from a renal perspective and reviewed the patient as an outpatient. JT was the lead consultant who was responsible for the patient's care when he was first admitted, prior to his ITU admission. All authors have read and approved the manuscript.

Funding

No funding declared.

Availability of data and materials

Not applicable. Reference list attached above. 


\section{Ethics approval and consent to participate}

Not applicable.

\section{Consent for publication}

Patient consent for the case report was obtained from the patient by STR. Written informed consent was obtained from the patient for publication of this case report and any accompanying images. Consent from the patient was obtained in 2018, at which point the patient was aged 19, hence no parental/guardian consent was obtained. A copy of the written consent is available for review by the editor of this journal.

\section{Competing interests}

The authors declare that they have no competing interests.

\section{Author details}

'Department of Gastroenterology, Imperial College Healthcare NHS trust, St Marys Hospital, London W2 1NY, England. ${ }^{2}$ Department of Surgery and Cancer, Imperial College London, W2 1NY London, England. ${ }^{3}$ University College Hospital, 235 Euston Road, Bloomsbury, London NW1 2BU, England. ${ }^{4}$ Imperial College Healthcare NHS trust, St Marys Hospital, London W2 1NY, England. ${ }^{5}$ Imperial College Healthcare NHS Trust, Hammersmith hospital, London W12 OHS, England.

Received: 3 April 2018 Accepted: 19 August 2019

Published online: 28 August 2019

\section{References}

1. Su C, Brandt L. Escherichia coli O157: H7 infection in humans. Ann Intern Med. 1995;123:698-707. https://doi.org/10.7326/0003-4819-123-9-19951101 0-00009.

2. Kaplan BS, Meyers KE, Schulman SL. The pathogenesis and treatment of hemolytic uremic syndrome. J Am Soc Nephrol. 1998;9(6):1126-33.

3. Tarr PI, Gordon CA, Chandler WL. Shiga-toxin-producing Escherichia coli and haemolytic uraemic syndrome. Lancet 2005;25;365(9464):1073-86.

4. Bell BP, Goldoft M, Griffin PM, et al. A multistate outbreak of Escherichia coli 0157: h7-associated bloody diarrhea and hemolytic uremic syndrome from hamburgers: the washington experience. JAMA 1994:2;272(17):1349-53.

5. Slutsker L, Ries AA, Greene KD, Wells JG, Hutwagner L, Griffin PM. Escherichia coli O157: H7 diarrhea in the United States: clinical and epidemiologic features. Ann Intern Med 1997;1;126(7):505-13.

6. Fakhouri F, Zuber J, Fremeaux-Bacchi V, Loirat C. Seminar:Haemolytic uraemic syndrome. Lancet. 2017. https://doi.org/10.1016/S0140-6736(17)3 0062-4.

7. Trachtman H, Austin C, Lewinski M, Stahl RA. Renal and neurological involvement in typical Shiga toxin-associated HUS. Nat Rev Nephrol 2012;1 8(11):658-69.

8. Kavanagh D, Goodship TH, Richards A. Atypical hemolytic uremic syndrome. Sem Nephrol. 2013:33(6):508-30.

9. Shiraishi M, Ichiyama T, Matsushige T, Iwaki T, Iyoda K, Fukuda K, Makata H, Matsubara T, Furukawa S. Soluble tumor necrosis factor receptor 1 and tissue inhibitor of metalloproteinase-1 in hemolytic uremic syndrome with encephalopathy. J Neuroimmunol 2008 30;196(1):147-52.

10. Kappler S, Ronan-Bentle S, Graham A. Thrombotic Microangiopathies (TTP, HUS, HELLP). Emerg Med Clin 20141;32(3):649-71.

11. Haspel RL, Jarolim P. The "cutting" edge: von Willebrand factor-cleaving protease activity in thrombotic microangiopathies. Transfus Apheresis Sci. 2005:32:177-84

12. Loirat C, Saland J, Bitzan M. Management of hemolytic uremic syndrome. Presse Med. 2012:41:115-35.

13. Thomas DE, Elliot EJ. Interventions for preventing diarrhea-associated hemolytic uremic syndrome: systematic review. BMC Public Health. 2013;13: 799. https://doi.org/10.1186/1471-2458-13-799.

14. Wong CS, Jelacic S, Habeeb RL, Watkins SL, Tarr PI. The risk of the hemolytic-uremic syndrome after antibiotic treatment of Escherichia coli O157: H7 infections. NEJM 2000;29;342(26):1930-6.

15. Dundas S, Todd WA, Stewart Al, Murdoch PS, Chaudhuri AK, Hutchinson SJ. The Central Scotland Escherichia coli O157: H7 outbreak: risk factors for the hemolytic uremic syndrome and death among hospitalized patients. Clin Infect Dis. 2001;33(7):923-31.

16. Orth D, Würzner R. Complement in typical hemolytic uremic syndrome Sem Thromb Hemost. 2010;36(6):620-4.
17. Lapeyraque AL, Malina M, Fremeaux-Bacchi V,et al. Eculizumab in severe Shiga-toxin-associated HUS. NEJM 2011;30;364(26):2561-3.

18. JT Kielstein G, Beutel SF, et al. Best supportive care and therapeutic plasma exchange with or without eculizumab in Shiga-toxin-producing E. coli O104: H4 induced haemolytic-uraemic syndrome: an analysis of the German STEC-HUS registry. Nephrol Dial Transplant. 2012;27(10):3807-15.

19. Ekinci Z, Bek K, Aytac MB, Karadenizli A, Hancer VS. Renal outcome with eculizumab in two diarrhea-associated hemolytic-uremic syndrome cases with severe neurologic involvement. HKJN 2014;31;16(2):46-9.

20. Pape L, Hartmann H, Bange FC, Suerbaum S, Bueltmann E, AhlenstielGrunow T. Eculizumab in typical hemolytic uremic syndrome (HUS) with neurological involvement. Medicine 201;94(24).

21. Tarr PI, Karpman D. Editorial commentary: Escherichia coli O104: H4 and hemolytic uremic syndrome: the analysis begins. Clin Infect Dis. 2012;55(6): 760-3.

22. Dundas S, Murphy J, Soutar RL, Jones GA, Hutchinson SJ, Todd WT. Effectiveness of therapeutic plasma exchange in the 1996 Lanarkshire Escherichia coli O157: H7 outbreak. Lancet 1999;16;354(9187):1327-30.

23. Greinacher A, Friesecke $S$, Abel P, et al. Treatment of severe neurological deficits with $\lg G$ depletion through immunoadsorption in patients with Escherichia coli 0104:H4-associated haemolytic uraemic syndrome: a prospective trial. Lancet. 2011;24(378):1166-73.

\section{Publisher's Note}

Springer Nature remains neutral with regard to jurisdictional claims in published maps and institutional affiliations.
Ready to submit your research? Choose BMC and benefit from:

- fast, convenient online submission

- thorough peer review by experienced researchers in your field

- rapid publication on acceptance

- support for research data, including large and complex data types

- gold Open Access which fosters wider collaboration and increased citations

- maximum visibility for your research: over $100 \mathrm{M}$ website views per year

At BMC, research is always in progress.

Learn more biomedcentral.com/submissions 